\title{
Moisés Bertoni: Ciência e Estado-Nação (1890-1929) ${ }^{1}$
}

\author{
Moisés Bertoni: Ciencia y Estado-Nación (1890-1929) \\ Moisés Bertoni: Science and Nation-State (1890-1929)
}

\author{
Ms. Wagner Henrique Neres Fiuza ${ }^{2}$
}

\begin{abstract}
Resumo
Poderia ser a ciência uma forma de afirmar, consolidar ou estremecer relações internacionais? Em que medida a ciência se produziu nesta relação entre nacional e internacional na América Latina no início do século XX? Estas perguntas surgiram na pesquisa sobre a obra de Moisés Bertoni durante o período em que viveu e publicou na República do Paraguai (1890-1929). Nascido na Europa, Bertoni escolheu o Paraguai para trabalhar e findar seus dias. Ali, empreendeu enorme trabalho científico de campo e fundou sua própria editora, a Ex Sylvis. A partir dali, publicava seus resultados e também recebia publicações do mundo todo. O financiamento estatal, mesmo que precário, estabeleceu estreitas relações entre o Estado e a produção intelectual de Bertoni. Não sem razão, ele e sua família representavam o Paraguai em congressos científicos internacionais, estabelecendo contatos e buscando afirmar um lugar para ele no circuito científico e para aquele país no concerto das nações. Em fase inicial, a pesquisa aponta a relação entre o esforço científico de perseguir leis e regras universais, e a delimitação dessas práticas em fronteiras nacionais. Neste sentido, o cientista Bertoni é co-participante da construção do estado-nação paraguaio, de suas significações identitárias e da fixação de suas fronteiras simbólicas.
\end{abstract}

Palavras-Chave: América Latina; Ciência; Moisés Bertoni; Paraguai.

\section{Resumen}

¿Podría ser la ciencia una forma de afirmar, consolidar o estremecer las relaciones internacionales? ¿En qué medida la ciencia se produjo en esta relación entre nacional e internacional en América Latina a principios del siglo XX? Estas preguntas surgieron en la investigación sobre la obra de Moisés Bertoni durante el período en que vivió y publicó en la República del Paraguay (1890-1929). Nacido en Europa, Bertoni eligió a Paraguay para trabajar y terminar sus días. Allí, emprendió enorme trabajo científico de campo y fundó su propia editora, la Ex Sylvis. A partir de allí, publicaba sus resultados y también recibía publicaciones de todo el mundo. El financiamiento estatal, aunque precario, estableció estrechas relaciones entre el Estado y la producción intelectual de Bertoni. No sin razón, él y su familia representaban a Paraguay en congresos científicos internacionales, estableciendo contactos y buscando afirmar un lugar para él en el circuito científico y para aquel país en el concierto de las naciones. En la fase inicial, la investigación apunta la relación entre el esfuerzo científico de perseguir leyes y reglas universales, y la delimitación de esas prácticas en fronteras nacionales. En este sentido, el científico Bertoni es co-participante de la construcción del estado-nación paraguayo, de sus significaciones identitarias y de la fijación de sus fronteras simbólicas.

Palabras clave: América Latina; la ciencia; Moisés Bertoni; Paraguay.

\footnotetext{
1 Artigo apresentado no Simpósio Temático “Cultura, Fronteira e Relações Internacionais" surante o II Seminário Latino-Americano de Estudos em Cultura - SEMLACult em Foz do Iguaçu/PR, Brasil, 2018.

${ }^{2}$ Mestre em História e Regiões (UNICENTRO); Doutorando no Programa de Pós-Graduação em História da Universidade Estadual do Oeste do Paraná (UNIOESTE); Guarapuava, Paraná, Brasil; wagnerunicentro@hotmail.com.
} 


\begin{abstract}
Would science be a way of affirming, consolidating or shaking international relations? To what extent did science occur in this relationship between national and international in Latin America at the beginning of the 20th century? These questions arose in the research on the work of Moisés Bertoni during the period in which he lived and published in the Republic of Paraguay (1890-1929). Born in Europe, Bertoni chose Paraguay to work and finish his days. There, he undertook an enormous field scientific work and founded his own editor, the former Sylvis. From there, he published his results and also received publications from around the world, especially from authors in America. The state financing, although precarious, established close relations between the State and the intellectual production of Bertoni. Not without reason, he and his family represented Paraguay in international scientific congresses, establishing contacts and seeking to establish a place for him in the scientific circuit and for that country in the concert of nations. In the initial phase, the research points to the ambivalent relationship between the scientific effort to pursue universal laws and rules, and the delimitation of those practices at national borders. In this sense, Bertoni is a co-participant in the construction of the Paraguayan nation-state, its identity significations and the fixation of its symbolic borders.
\end{abstract}

Keywords: Latin America; Science; Moisés Bertoni; Paraguay

\title{
1. Introdução
}

O final do século XIX e o primeiro quarto do século XX foi o apogeu das construções nacionalistas no mundo ocidental. O historiador Eric Hobsbawm, em suas grandes antologias acerca do mundo moderno e contemporâneo, classificou uma parte deste período como A Era dos Impérios (1875-1914), ou seja, uma época de relativa paz e de intensa expansão do capitalismo que definiu os jogos de poder no mundo a partir de seu maior resultado: a Grande Guerra (1914-1918). Os grandes atores políticos do período foram os estados-nação, que intensificaram a corrida por territórios coloniais em todo o mundo, num processo histórico conhecido como imperialismo (HOBSBAWM, 1987).

Assim, no fim do século XIX e início do século XX, a projeção econômica e cultural europeia sobre o mundo foi um novo avanço colonial, mas agora sob moldes imperiais e capitaneada pela concorrência entre estados-nação em diferentes setores, como o militar, e econômico, o científico e o simbólico. Um dos principais meios utilizados para essa disputa consiste no grande avanço tecnológico e o estabelecimento da ciência como paradigma definitivo de organização e racionalização da economia. Isso significa a perseguição às regras e métodos universais para atingir uma verdade científica, que racionalizasse e classificasse o mundo e o conhecimento. Entretanto, se considerarmos que nações são acima de tudo ideias, representações que mobilizam sujeitos, grupos e instituições a estabelecer e defender limites, símbolos, fronteiras, abre-se uma possibilidade de análise na relação entre nacional/universal na relação entre estabelecer nações e fazer ciência.

Neste sentido, o objetivo deste texto é lançar algumas perguntas iniciais para pensar a historicidade de cientistas como construtores de fronteiras nacionais. Especificamente neste texto, abordamos aspectos da vida e obra de Moisés Bertoni (1857-1929), cientista suíço- 
paraguaio que reconfigurou sua vida ao imigrar para a América, e cuja vida, obra e experiência permite problematizar algumas das relações entre a ciência e o Estado.

\section{Nações e Nacionalismos}

Para o historiador britânico Eric Hobsbawm as relações entre estados-nação têm uma longa historicidade. Entretanto, a segunda metade do século XIX possui uma alteração importante nas relações internacionais. Segundo ele, até 1870 "se poderia afirmar que o ganho de urna nação-Estado não significava necessariamente uma perda para outra”, contudo, após o Congresso de Berlim em 1878 "ganhou terreno a espécie de nacionalismo para a qual as demais nações eram francamente ameaças ou vítimas" (HOBSBAWM, 1987, p. 135). Para entender o fenômeno desse nacionalismo, Hobsbawm levou em consideração tanto as ditas pessoas comuns que se sentiam parte de um mesmo grupo étnico ou linguístico, quanto o uso dessas relações por um Estado administrativo, o que potencializou a ascensão de uma burocracia estatal e uma concepção de cidadania como dever cívico (HOBSBAWM, 2005).

Sua análise considera que essa mudança está relacionada às mudanças mais amplas da própria economia mundial, como a crescente concentração de captais, industriais e bancários, cujas consequências reconfiguraram a escala de poder até então concentrada no parque industrial da Grã-Bretanha - que foi o destino de metade de todas as exportações somadas de África, América Latina e Ásia em 1860. Até mesmo o declínio do domínio industrial inglês, na medida em que outros Estados passaram pelo processo de industrialização na Europa e mesmo na América e na Ásia, como o Estados Unidos da América e o Japão, reforçou e até aumentou a dependência de seus serviços financeiros, comerciais e de sua marinha mercante (HOBSBAWM, 1987, p. 51).

Esse grande movimento de pluralidade de centros industriais concomitante à concentração de capitais coincidiu com outras transformações, como a revolução tecnológica, a mudança na estrutura e no modus operandi da empresa capitalista, a expansão da produção dos bens de consumo, o crescimento do setor terciário e a cada vez mais íntima relação entre economia e política. Neste contexto, o autor nos diz que "ocorreu a fusão da rivalidade política entre os Estados com a concorrência econômica entre grupos nacionais de empresários (HOBSBAWM, 1987, p. 53).

Para o autor, este é um fenômeno complexo na medida em que assume muitas formas históricas diferentes, pois estão ancorados em uma problemática fórmula na qual Estados correspondem a nações, entendidas por ele como grupos que mobilizam uma mesma história e 
compartilham um mesmo idioma. Entretanto, essas relações não são estáveis, ou seja, há estados sem nações e nações sem estados, ou ainda, um estado de múltiplas nações - esta, por sinal, uma configuração histórica da qual emergem diversos movimentos separatistas e conflitos genocidas na contemporaneidade, demonstrando a face mórbida dos nacionalismos resultante do processo histórico específico do adensamento da relação entre Estados e nações (HOBSBAWM, 2005).

Já para Benedict Anderson, a emergência do capitalismo também é considerada fundamental para pensar as relações entre estados e nações, que se deram logo no início da era moderna. Para ele, um dos elementos principais para a consolidação das nações na Europa foi a invenção da imprensa, que gera um grande estímulo à mídia impressa e, por conseguinte, à uma expansão do mercado das línguas vernáculas. Esta espécie de "capitalismo editorial" permitiu criar, manter e circular uma "comunidade imaginada", nunca tão grande nem tão pequena que não possa ser sustentada por símbolos e valores a ela associados. Forja-se, portanto, uma cultura nacional, um senso de "camaradagem horizontal" que reconhece um outro como parte de si a partir de um vínculo nacional. Para Anderson, essa comunidade se desenvolveu a tal ponto que sua expressão máxima é uma pessoa ser capaz de dar sua vida por sua pátria (ANDERSON, 1989).

As nações como comunidades imaginadas se tornam alvo de disputas no presente e no passado a fim de reivindicar limites, territórios, conquistas, culturas, enfim, de tudo aquilo que possa ser considerado como parâmetro de valor no contexto em que os litígios acontecem. Também recebem as mais diferentes imaginações, não raro assumindo formas totalmente novas e (re)significadas. Sob esta perspectiva, os estados-nação não devem ser vistos apenas como consequências de um grande processo histórico capitalista, nem subproduto imaginativo e meramente comemorativo de mudanças econômicas. Antes, são tanto produto quanto produtoras de sentidos em litígio, ancorados em diferentes relações de poder.

Essa perspectiva se aproxima da arqueologia do Estado moderno de Michel Foucault que o pensa a partir das relações de poder que se alteraram entre o fim da Idade Média e o crepúsculo do século XIX. Neste grande período, o autor ressalta que a ascensão do Estado moderno está ligada ao monopólio da violência que se deslocou da repressão com foco no indivíduo para a instituição de diferentes tecnologias de poder e de todo um aparato repressivo como escolas, sanatórios, prisões, hospitais, etc. Nesta perspectiva, saber e poder caminham lado a lado, e o poder não é apenas repressivo, mas também produtivo. Por isso surgem diferentes dispositivos do aparato jurídico que normatizaram condutas, corpos e ações, e assim garantiram mecanismos institucionais de controle e classificação para agir 
como Estado e em nome dele. Estas mudanças fizeram parte de um processo social mais amplo no qual as próprias relações capitalistas demandaram o crescimento, a utilidade e a docilidade dos corpos (FOUCAULT, 1987).

Nesta perspectiva, a nação pode ser pensada, portanto, enquanto um discurso, ou seja, como continuidades e rupturas históricas em suas relações de saber e poder e seus efeitos de sentido (FOUCAULT, 2014). Nesta leitura, as construções discursivas do ser nacional se confrontam sob a forma de projetos de Estado, de nação e de identidades nacionais. Esses discursos produzem efeitos de sentido, que almejam instituir uma verdade acerca da origem, das fronteiras e dos representantes de um determinado país. A perspectiva histórica de uma pesquisa sobre um estado-nação permite, portanto, analisar as relações de poder constituídas num determinado contexto, percebendo como sujeitos mobilizam, defendem, refutam ou se rendem ao discurso nacional em voga. Neste sentido, é importante pesquisar sobre como os sujeitos que atuaram nos e para os grandes discursos nacionais e nacionalizantes no final do século XIX e início do século XX. Também é pertinente perguntar como este processo de disputas entre estados-nação criou e desenvolveu outros campos de solidariedades e disputas, instituições, mecanismos de proteção e de intercâmbio de conhecimentos e informações.

\section{Moisés Bertoni, a ciência e a afirmação de fronteiras nacionais}

Neste amplo contexto emergiram sujeitos como Mosé Giácomo Bertoni (1857-1929), imigrante suíço radicado no Paraguai no período de 1890-1929. Ao mudar-se para a América, tornou-se Moisés Santiago Bertoni, e vislumbrou uma possibilidade de ir à campo e experimentar suas ideias acerca da sociedade, assim como estar no próprio campo de experimentação científica que a Mata Atlântica proporcionava. Estabeleceu-se em uma área de 199 hectares às margens do Rio Iguaçu, aonde conduziu suas pesquisas e instituiu um centro científico denominado Puerto Bertoni (BUTTURA; NIEMEYER, 2012).

Por centro científico, se entende que Puerto Bertoni foi um ponto de inflexão e circulação de conhecimento científico produzido em todo o mundo, mas predominantemente na Europa e na América. Com melhoramentos como uma linha telegráfica e uma conexão de correios, Bertoni comprava e remetia publicações, correspondências, ofícios, etc. Seus temas de interesse abrangeram a geografia, a meteorologia, a botânica, a antropologia e ainda outros, assinando mais de 500 livros publicados, assim como reunindo atas, anais, cartas e livros que perfizeram uma biblioteca com mais de 17.000 itens. As vastas áreas de interesse do autor e sua quantidade de publicações levaram Moisés Bertoni a ser considerado por seus biógrafos como um dos últimos enciclopedistas (FLECK, 2007). 
Neste contexto, um homem europeu assumiu uma nova identidade nacional, a princípio não conflitante com sua identidade anterior, e a partir disso passa a buscar a ciência universal nas matas paraguaias. Neste ímpeto, Bertoni estabeleceu um importante centro científico em um país periférico, devastado pela guerra havia poucas décadas, e cujas elites locais ansiavam por estabelecer o que era o estado-nação paraguaio e qual o seu lugar na hierarquia das nações.

Este, aliás, foi o ambiente intelectual que Bertoni viveu no Paraguai: debates sobre a reconstrução de uma identidade nacional. Isso porque o país ainda se recuperava econômica e moralmente após ser devastado pela chamada Guerra da Tríplice Aliança (1864-1867), em que Brasil, Argentina e Uruguai uniram forças para derrotar o Paraguai, naquele que ficou conhecido como o maior conflito armado da América Latina. Os debates, entre outros tópicos, abrangiam qual era o papel do elemento indígena na formação nacional paraguaia, ou seja, em que medida a herança indígena deveria ser negada ou realçada naquele momento de reconstrução da identidade nacional (BARRATI, 2003). A importância dos intelectuais nesse processo, os quais receberam (ou se deram) a missão de apontar novos caminhos para reconstituir a moral de uma nação tanto no cenário nacional, para a própria população, quanto internacional, no grande concerto das nações.

Segundo Moreira, toda uma intelectualidade latino-americana produziu trabalhos no formato de "radiografias" e "diagnósticos" sobre os problemas contemporâneos e sua relação com culturas regionais/continentais. Este conjunto caracteriza-se por "escritos identitários, propondo um projeto social, político, econômico ou cultural, representando idéias-forças dinâmicas para o pensamento de todo o continente, no intento de responder ao permanente impacto mundial da modernização" (MOREIRA, 2008, p. 1). Sendo assim, podemos dizer que Moisés Bertoni, ao seu modo, fez parte desta rede de ideias.

Moisés Bertoni foi um autor que, inspirado no modelo de produção de conhecimento cartesiano, acreditava na ciência como um conhecimento produzido a partir de um método neutro e imparcial, experimentável e comprovável, que buscava uma verdade objetiva e irrefutável, com validade universal, sem fronteiras e sem limitações que não às da própria razão. Para ele, ser um cientista incluía estar ou acompanhar a dianteira das inovações no mundo científico. Para cumprir esta regra, ele usava duas estratégias principais: procurava levantar a maior bibliografia possível e também participava de congressos científicos. Com isso, buscava orientar suas pesquisas científicas com perguntas atuais e de posse do instrumental conceitual e empírico construído em pesquisas de outros lugares do mundo. 
Assim, tanto Moisés Bertoni quanto seus filhos participavam de congressos científicos internacionais como delegados paraguaios. $^{3}$ Cada vez que palestrava ou era convidado a participar de um evento, havia implícita uma representação do estado nacional paraguaio. Isso quer dizer que existe um jogo entre a pretensão ao conhecimento universal da ciência e à sua representação em termos nacionais, com fronteiras que buscam fixar valores, identidades e interesses. Moisés Bertoni era um europeu que, ao ser radicado no Paraguai, passou a produzir em nome da ciência universal, mas também em nome da nação paraguaia.

Ora, se se considera as nações como discursos, o que eles inscrevem nos corpos, nas paisagens, nos sujeitos? E, por outro lado, como são inscritos? Na medida em que estas questões são colocadas, não se pode considerar fronteiras como elementos naturais, mas sobretudo simbólicos e em disputa, sendo eles tão instáveis quanto os estados-nação que buscam representar. Se estabelece, portanto, um jogo de demarcação de identidades pela diferença (WOODWARD, 2000), no qual se necessita de processos de vigilância e celebração para reafirmar não apenas quem está dentro e quem está fora, mas quem pertence e quem não pertence às fronteiras simbólicas de um determinado grupo, indicando uma relação estreita desses processos entre estados-nação, a ciência e seus representantes: os cientistas.

\section{Conclusões}

A breve exposição que foi discutida aqui partiu da premissa de que apesar de os Estados-nação se apresentarem como regularidades no tempo e no espaço, estão sujeitos à uma constante disputa sobre suas fronteiras, bem como seu lugar no rol das nações no presente e no passado. Neste sentido, no lastro de alguns estudos que já identificaram a atuação dos "intelectuais platinos", abre-se uma perspectiva de pesquisa interessante acerca dos homens da ciência que fizeram circular um saber científico com cores nacionais na América Latina no final do século XIX e início do século XX.

Perceber essas relações na trajetória de cientistas e suas participações em congressos internacionais nos introduzem a uma contradição entre nacional/internacional, que até o momento ainda se apresenta como limite nesta pesquisa, mas que pode e deve ser desenvolvida em outros textos e trabalhos.

\section{Referências}

\footnotetext{
${ }^{3}$ Por exemplo o Congresso Científico Internacional realizado no Rio de Janeiro, em 1906; ou ainda o Congresso Internacional de Americanistas de 1922, também realizado no Rio de Janeiro.
} 
ANDERSON, Benedict. Comunidades Imaginadas, nação e consciência nacional. São Paulo: Ática, 1989.

BARATTI, Danilo. Moisés Santiago Bertoni y la generación nacionalista-indigenista paraguaya. Bulletin Société Suisse des Américanistes, n.66-67, p.41-47. 2002-2003.

BERTONI, Moisés. La Civilización Guarani. Puerto Bertoni: Ex Sylvis, 1922.

FLECK, Eliane Cristina Deckmann. A abordagem historiográfca dos séculos XIX e XX sobre a atuação de médicos e boticários jesuítas na América platina no século XVIII. História, Ciências, Saúde - Manguinhos, Rio de Janeiro, v.21, n.2, abr.-jun. 2014, p. 667685.

FOUCAULT, Michel. A Ordem do Discurso. São Paulo: Edições Loyola, 2014.

. Vigiar e Punir. Tradução de Raquel Ramalhete. Petrópolis: Vozes, 1987.

Terra, 2014.

Sobre a Geografia. In: Microfísica do Poder. São Paulo: Editora Paz e

HOBSBAWM, Eric. A Era dos Impérios 1875-1914. Rio de Janeiro: Paz e Terra, 1987.

. Nações e Nacionalismos desde 1780. Rio de Janeiro: Paz e Terra, 1990.

MOREIRA, Luís Felipe Viel. A Historiografia Brasileira e o Revisionismo Histórico Platino. ENCONTRO INTERNACIONAL DA ANPHLAC, VIII, Vitória. Anais..., Vitória, 2008.

NIEMEYER, Aline; BUTTURA, Evaldo. Moisés Bertoni: Uma vida para a Ciência. Foz do Iguaçu: Editora Epígrafe, 2012.

WOODWARD, Kathryn. Identidade e diferença: uma introdução teórica e conceitual. In: SILVA, Tomaz Tadeu da (Org); HALL, Stuart; WOODWARD, Kathryn. Identidade $e$ Diferença: a perspectiva dos estudos culturais. $4^{\text {a }}$. Ed. Petrópolis: Vozes, 2000. P. 7-72. 